\title{
O Estado, o mercado editorial e o professor no processo de seleção dos livros didáticos
}

\author{
ELIECÍLIA DE FÁTIMA MARTINS \\ NORMA ALMEIDA DE OLIVEIRA DE SALES \\ CLEBER ALVES DE SOUZA ${ }^{* * *}$
}

\section{RESUMO}

O livro didático é uma poderosa ferramenta pedagógica. Além de ser uma fonte de pesquisa e orientação para professores e alunos, exerce papel de grande importância na política educacional e na aprendizagem, transmitindo conhecimentos, ideias e valores sobre determinados conteúdos. Implicitamente, o livro didático abrange interesses sociais, políticos, econômicos e culturais. Nesse sentido, o presente trabalho objetiva discutir algumas consideraçóes sobre o processo de seleção dos livros aprovados pelo Plano Nacional do Livro Didático (PNLD), principalmente os utilizados na rede pública de ensino, analisando os aspectos políticos, econômicos e pedagógicos que determinam essa escolha, enfatizando a posição do Estado, das editoras e dos professores envolvidos nesse processo.

Palavras-chave: livros didáticos, professores, políticas educacionais, currículos.

\footnotetext{
* Professora na área de Educação em Ciências e Design de Moda da Universidade Salgado de Oliveira (Universo), Campus Goiânia (eliecilia@gmail.com.br).

${ }^{*}$ Professora do Ensino Fundamental da Rede Estadual de Goiás (odontomedy@hotmail.com). *** Atua no corpo administrativo da equipe de coordenaçáo de professores da Universidade Salgado de Oliveira (Universo), Campus Goiânia (clebermcb@hotmail.com).
} 


\section{RESUMEN}

El libro didáctico es una poderosa herramienta pedagógica. Además de ser una fuente de investigación y orientación para profesores y alumnos, ejerce un papel de gran importancia en la política educativa y en el aprendizaje, transmitiendo conocimientos, ideas y valores sobre determinados contenidos. Implícitamente, el libro didáctico abarca intereses sociales, políticos, económicos y culturales. En este sentido el presente trabajo tiene como objetivo discutir algunas consideraciones sobre el proceso de selección de los libros aprobados por el Plan Nacional del Libro Didáctico (PNLD), principalmente los utilizados en la enseñanza pública, analizando los aspectos políticos, económicos y pedagógicos que determinan dicha elección, enfatizando la posición del Estado, de las editoriales y de los profesores implicados en este proceso.

Palabras clave: libros didácticos, profesores, políticas educativas, currículos.

\section{ABSTRACT}

A textbook besides being a teacher's and student's source of research and guidance is also a powerful teaching tool. It takes on great importance in educational policies and in the learning process, transmitting knowledge, ideas and values about certain subjects. Implicitly, a textbook deals with social, political, economical and cultural interests. This article will present some notes about the selection process of textbooks approved by the National Textbook Plan (PNLD), mainly used in public schools. It analyzes political, economic and pedagogical aspects that determine this choice, emphasizing the position of the Administration, the publishers and the teachers involved in that process.

Keywords: textbooks, teachers, educational policies, curricula. 


\section{INTRODUÇÃO}

O livro didático é entendido como um material impresso, estruturado, destinado ao processo de aprendizagem ou formação acadêmica, sendo utilizado de forma sistemática. É possível, a partir daí, distingui-lo de outros livros e materiais escolares, como os textos-base, as antologias e os livros de referências. Tal procedimento não implica classificar os livros anteriormente citados como náo educativos, ou que o professor náo possa optar por usá-los no lugar dos chamados "livros didáticos". Trata-se apenas de estabelecer um campo de estudo e uma linguagem técnica de trabalho (Oliveira; Guimarães; Bomery, 1984).

Em continuidade a essa delimitação, pode-se dizer que a importância do livro didático não se resume ao aspecto pedagógico nem à influência na aprendizagem e/ou ao desempenho dos alunos. Como referência de acesso ao conteúdo disciplinar da escola, ele pode também orientar os processos de desenvolvimento da personalidade do educando, pois no aspecto ideológico, a sociedade reproduz, no livro, seus valores culturais, políticos e econômicos (Martins; Guimarães, 2002, p.10). Nesse cenário, surge um personagem que é de grande importância social: o professor. Esse profissional deveria ser o responsável pela escolha do material a ser utilizado em sala de aula.

Mas em um contexto como o do Brasil, cujas políticas educacionais são orientadas pelas Organizaçóes Internacionais (OIs), a questão da escolha desse tipo de livro torna-se complexa, indo além da opção apresentada pelo professor. Esta complexidade deriva da massificação do ensino fundamental, e ao mesmo tempo da busca da qualidade escolar para uma quantidade significativa de crianças.

Portanto, este trabalho tem como objetivo analisar o processo de seleção dos livros didáticos na perspectiva dos fatores externos e internos à escola. Inicialmente, este estudo é marcado pela análise do processo de escolha de tais livros na perspectiva do projeto do Estado brasileiro e dos objetivos que ele deveria alcançar, de acordo com o ideário oficial e de intelectuais ligados à educação. Em seguida, o livro didático é discutido sob o ponto de vista dos interesses mercadológicos. A partir da relação estabelecida entre a indústria editorial e o poder público, buscase desvendar os interesses e a influência das editoras nesse processo de seleção. Por último, são apresentadas questóes referentes à escolha do livro didático, realizada pelos professores do ensino fundamental da rede pública, tendo como foco os aspectos pedagógicos e a formaçáo acadêmica desses profissionais, procurando compreender a seleçáo, desde a avaliação do MEC, por meio do PNLD, até a chegada do livro à escola. 


\section{AS POLÍTICAS DOS LIVROS DIDÁTICOS NO BRASIL}

Qualquer política ligada à escolha do livro didático no Brasil - deliberadamente planejada pelo governo, implementada, ou existente de fato - está condicionada a uma série de fatores. O resultado, quase sempre, interfere no grau de independência e liberdade desta escolha, facilitando o prognóstico de muitos dos seus contornos. Na opinião de Apple (1997), estudioso da área, a constituição do "conhecimento oficial" escolar e, em particular, dos livros didáticos está fortemente entrelaçada com as relaçóes de poder estabelecidas historicamente com base no contexto político, econômico e cultural. Suas ideias podem ser reafirmadas ao analisarmos as políticas brasileiras relacionadas ao livro didático no período do Estado Novo e nos dias atuais.

Conflitos envolvendo os livros-texto são freqüentemente substitutos para problemas mais amplos de relação de poder. [...] Eles, por seu conteúdo e forma, significam construçóes particulares da realidade, modos particulares de selecionar e organizar um vasto universo de conhecimento possível. Incorporam [...] uma seleção feita por alguém, com sua particular visão sobre o conhecimento legítimo e a cultura, uma seleção que no processo de privilegiar o capital cultural de um grupo desprivilegia o de outro. (p.77)

A trajetória oficial do livro didático no Brasil teve início em 1929 com a criação do Instituto Nacional do Livro (INL) que, de imediato, não saiu do papel. Somente em 1938, entrou na pauta do governo por meio do Decreto-Lei n. 1.006, de 30/12/38, que instituiu a Comissão Nacional do Livro Didático (CNLD). A partir de então, estabeleceu-se a primeira política de legislação, controle de produção e circulação do livro didático no País (Brasil, 2008). Esse controle pautava-se mais no caráter político e ideológico brasileiro do que no caráter didático.

Nesse momento histórico, estabeleceu-se uma série de legislaçóes, visando à constituição do que na época denominava-se "consciência nacional", "construção da nacionalidade" e afirmação do "Estado Nacional". O livro didático não escapou às discussóes levantadas nesse período e acabou se tornando, potencialmente, um dos grandes veículos de transmissão do ideário Estado Novista (ibid., p. 35).

É relevante destacar que a "democratização" do ensino público foi um compromisso do Estado Novo e, em razão dessa "generalizaçáo", o governo tomou o cuidado de orientar o modelo de cidadão que lhe interessava naquelas circunstâncias:

A educação, longe de ser neutra, precisa tomar partido, melhor, partir de uma filosofia e seguir uma escala de valores; ela precisa ser conduzida pelas diretivas 
morais, políticas e econômicas do sistema que representa as bases de nossa nação e que por isso mesmo está sob a proteção, o controle e a defesa do Estado (Ministério da Educação, 1937 apud Freitag et al., 1989, p. 25).

O período autoritário do Estado Novo tornou a avaliação do livro didático de responsabilidade única do órgão de execução, estabelecendo critérios de aprovaçáo do livro a partir do projeto de soberania nacional. Para melhor exemplificar esses critérios basta observar as ideias presentes no Decreto-Lei n. 1006 de dezembro de 1938, que apresenta os aspectos que impediam a autorizaçáo de determinada obra:

a) O livro que atente de qualquer forma, contra a unidade, a independência ou a honra nacional;

b) Que contenha de modo explícito ou implícito, pregação ideológica ou indicação da violência contra o regime político adotado pela nação;

c) Que envolva qualquer ofensa ao chefe da nação, ou às autoridades constituídas, ao Exército, à Marinha, ou às demais instituições nacionais;

d) Que despreze ou escureça as tradições nacionais, ou tente deslumbrar as figuras dos que se bateram ou se sacrificaram pela pátria;

e) Que encerre qualquer afirmação ou sugestáo que induza ao pessimismo quanto ao poder e ao destino da raça brasileira;

f) Que inspire o sentimento da superioridade ou inferioridade do homem de uma regiāo do país com relação às demais regiōes;

g) Que incite o ódio contra as raças e as naçóes estrangeiras;

h) Que desperte ou alimente a oposição e a luta entre as classes sociais;

i) Que procure negar ou destruir o sentimento religioso, ou envolva combate a qualquer confissão religiosa;

j) Que atente contra a família, ou pregue ou insinue contra a indissolubilidade dos veículos conjugais;

k) Que inspire o desamor à virtude, induza o sentimento individual, ou combata as legítimas prerrogativas da personalidade humana.

Em face das políticas dessa natureza, as diversas pesquisas sobre o livro didático no ensino fundamental têm mostrado, não só no Brasil como em outros países, como esse material passou a ser o principal controlador do currículo (Soares, 2001). Com efeito, a atuação do atual Programa Nacional do Livro Didático (PNLD) vem reforçar essa postura do governo brasileiro. 
O Estado, por meio do Plano Decenal de Educação para Todos (Brasil, 1993), menciona uma política do livro - "Programa de Avaliação do Livro Didático" -, que, segundo esse documento, deve assegurar a qualidade do conteúdo dos livros didáticos. O Plano Nacional de Educação (Brasil, 1998, p. 33) reforça o proposto: "Manter e consolidar o programa de avaliação do livro didático criado pelo Ministério da Educação", ou seja, o PNLD.

Por intermédio do PNLD, e de posse do seu discurso da qualidade educacional, o governo intensificou a atençáo ao livro didático. Apoiado nele - e associado a outras políticas, como as avaliaçóes nacionais e os Parâmetros Curriculares Nacionais - os órgáos educacionais buscam regular e controlar, de modo explícito, o campo do saber escolar.

A questão da "qualidade" do livro didático, defendida pelo Mistério da Educação, é bem explícita: como garantia da "boa escolha" pelo professor, o sistema de ensino (representado pelo MEC) realiza uma "pré-seleção" desse material. O resultado pode ser conferido no Guia do Livro Didático (Brasil, 2001), que contém resenhas de todos os livros recomendados, agrupadas por áreas do conhecimento.

Considerando esse processo de avaliação dos livros, o MEC - ao aprovar algumas obras e excluir outras - mostra o que e como se deve ensinar, determinando visivelmente a forma e o conteúdo do livro didático atual. Em 1998, por exemplo, a avaliação excluiu 50,23\% dos livros inscritos (Moraes, 1998). Segundo os autores desses livros, o MEC considera só uma linha de ensino, o construtivismo, e exclui aqueles que seguem outras correntes, alegando incoerência metodológica.

Desse modo, percebe-se, nos livros aprovados, certa padronização de conteúdos, de atividades e de concepçôes, determinando um currículo rigidamente estabelecido pelo processo de seleção. Professores e alunos acabam tendo poucas opçóes, pois os livros parecem todos iguais. A escolha, nesse sentido, sai da dinâmica do processo, que é caracterizada como construçáo crítica e reflexiva, no sentido da participação social.

Em seu discurso, o PNLD destaca a necessidade da participação democrática do professor no processo de seleçáo dos livros didáticos, o que exigiria, desse profissional, o domínio de determinados saberes, critérios, competências, entre outros itens, capacitando-o a realizar uma escolha em conjunto com seus colegas de trabalho. Mas o próprio MEC preconiza: "O princípio de livre escolha pelo professor esbarra em sua insuficiente habilitação para avaliar e selecionar" (Brasil, 1993, p.25). 
A divulgação, pelo MEC, de que professores e diretores participam da seleção dos livros didáticos, leva a sociedade a crer que esses profissionais são os grandes responsáveis pela escolha do material usado pelos alunos. Nesse caso, tais publicaçôes supririam as necessidades do processo de aprendizagem. Mas, parece não ser essa a prática real.

Apesar de o livro didático náo ser visto como um elemento neutro na educação do País mantém-se a ilusão de que o professor, exercendo sua "autonomia", pode escolher o melhor livro a ser utilizado. Essa escolha, entretanto, estaria condicionada a um aperfeiçoamento na sua formação, que lhe forneceria elementos para discernir, entre os livros disponíveis, o mais adequado.

A não-participação real dos educadores pode ser compreendida, considerando as ideias de Apple (1995, p.82) quando afirma que o livro didático tem-se tornado um instrumento de controle do Estado. "Pouca coisa é deixada para a decisáo do professor, à medida que o Estado controla cada vez mais os tipos de conhecimentos que devem ser ensinados, os resultados e os objetivos deste ensino e a maneira segundo a qual este deve ser conduzido". Para Miranda e Luca (2004), o livro "comanda" várias práticas pedagógicas, manipula “informaçóes”, e até a forma como estas devem ser trabalhadas ou apresentadas.

É importante ressaltar: muitas das orientações assumidas pelos Estados, hoje, nos países em desenvolvimento, são determinadas pelos Organismos Internacionais (OIs). Pressupondo que o governo controla a produção e distribuição de livros didáticos, determinando, em grande parte, o que será ensinado nas escolas, é possível concluir: o investimento em livros torna-se, além de mais barato, mais eficiente na consecução dos objetivos dos OIs, o que possibilita o controle do trabalho docente, pois é comprovado que o livro didático é o instrumento "oficial" utilizado pelo professor (Scaff; Senna, 2000; Freitag et al., 1993).

No Brasil, esse tipo de livro é o único que a maioria da população brasileira conhece ao término da escola básica. Geralmente, o indivíduo perde contato com a leitura. Assim, esse livro se constitui, em relação a outros, em poderosa ferramenta política, ideológica e cultural, pois reproduz e representa os valores da sociedade quanto à visão da ciência, da história, da interpretação de fatos e do próprio processo de transmissão do conhecimento.

Portanto, considerando o que foi apresentado, a seleção dos livros didáticos representa uma responsabilidade de natureza social e política, pois ela nasce com a própria escola. Uma tarefa coletiva que não pode ser limitada a um grupo de especialistas responsáveis por analisar os livros e recomendá-los aos professores. 


\section{A SELEÇÃO DO LIVRO DIDÁTICO E SEUS ASPECTOS MERCADOLÓGICOS}

A indústria do livro no Brasil não depende de subsídios públicos para existir, mas seu principal consumidor é o Estado. A mercadoria principal das editoras são os livros didáticos, adquiridos por meio do Fundo Nacional de Desenvolvimento da Educação (FNDE).

O MEC é o maior comprador de livros do mundo, de acordo com Alexandre Serwy, Coordenador-Geral do Programa, de 1995 a 2005, e os recursos investidos na sua aquisição totalizam $\mathrm{R} \$ 3.894 .840 .129,00$, como mostra a tabela 1 .

Tabela 1 - Histórico de recursos investidos pelo

PNLD sobre o total de livros adquiridos

\begin{tabular}{crc}
\hline Programa/Ano & $\begin{array}{c}\text { Total de Livros } \\
\text { Adquiridos }\end{array}$ & $\begin{array}{c}\text { Recursos } \\
\text { (em R\$) }\end{array}$ \\
\hline PNLD/1995 & 56.973 .686 & $125.655 .576,00$ \\
PNLD/1996 & 80.267 .799 & $196.408 .626,00$ \\
PNLD/1997 & 84.732 .227 & $223.251 .105,00$ \\
PNLD/1998 & 84.254 .768 & $253.871 .511,00$ \\
PNLD/1999 & 109.159 .542 & $373.008 .768,00$ \\
PNLD/2000 & 72.616 .050 & $249.053 .552,00$ \\
PNLD/2001 & 130.283 .354 & $474.334 .699,00$ \\
PNLD/2002 & 120.695 .592 & $539.040 .870,00$ \\
PNLD/2003 & 57.024 .873 & $266.128 .366,00$ \\
PNLD/2004 & 119.287 .883 & $574.839 .852,00$ \\
PNLD/2005 & 111.189 .126 & $619.247 .203,00$ \\
\hline TOTAL & 1.026 .484 .900 & $3.894 .840 .129,00$
\end{tabular}

Fonte: Serwy (2005).

Em 2006, o investimento no PNLD foi de R \$ 563,7 milhóes, e, em 2007, foram gastos R \$ 661 milhóes (Brasil, 2008).

Esses dados mostram porque o PNLD se constitui no maior programa de distribuição de livros do mundo, e também um dos mais disputados "filóes" do mercado editorial brasileiro; filáo que está concentrado nas mãos de poucas editoras. Em 2004, por exemplo, 184 coleçóes foram aprovadas e negociadas com 15 editoras, que dividiram os recursos reservados exclusivamente para a compra dos livros. Em 
2005 foram aprovadas 92 coleçóes de 13 editoras, sendo que todas tiveram coleçóes aprovadas também em 2004.

Analisando esses fatos, fica claro o estabelecimento do livro didático como mercadoria. Como tal, em uma sociedade capitalista, está invariavelmente submetido às leis de mercado, implicando também vencer a concorrência, atender os consumidores e a demanda do produto.

No que se refere ao consumidor, inicialmente é o MEC, por intermédio do FNDE, que, com sua avaliação e critérios bem definidos, recebe o maior número de editoras (concorrentes entre si) para a submissão dos "produtos": os livros. Tendo em vista a posição privilegiada que esse impresso assume no mercado editorial, as editoras tendem a atender aos critérios do MEC, aplicando em seus livros as mesmas características dos anteriormente aprovados pelo PNLD (Soares, 2001), ou seja, adequam o "produto" às exigências do consumidor. Depois da aprovação dos livros, as editoras passam a ter menor concorrência e seu público-alvo passa a ser o professor que, com base nos livros apresentados no Guia do Livro Didático, escolhe qual coleção irá adotar.

A "guerra” por esse mercado táo lucrativo acaba originando denúncias de que, em certas localidades, a escolha, na escola, poderia ser tendenciosa e unidirecional, como no caso de uma cidade que optou pelos mesmos livros para todas as escolas do município. Nesse caso, foi constatada a pressão de três editoras dominantes. Enquanto o Guia do MEC oferecia 36 opçóes, os professores só conheceram três ou quatro publicaçóes: as dos catálogos dessas editoras. Uma editora chegou a criar uma versão do Guia do MEC, contendo somente as publicaçóes do seu catálogo, para que os professores confundissem os dois guias. Outra editora ofereceu benefícios, como promessas de melhoramento da quadra de esportes, em troca da opçáo, por parte da escola, de um determinado livro didático. O MEC acrescenta: um código de ética serviria para garantir a transparência do processo de compra, caso esses exemplos persistam. Em ação mais concreta, existe a Portaria Normativa n. 7, de 5 de abril de 2007, que dispóe sobre as normas de conduta para o processo de execução dos Programas do Livro (Brasil, 2007), e que, na prática, deve ser cumprida.

As editoras são empresas que fabricam produtos mercadológicos. No caso dos livros didáticos, eles são produzidos para um mercado com expectativas e demandas definidas (Lindoso, 1994), que serão estabelecidas com base na escolha feita pela escola, e finalizando nas negociações com o FNDE.

A escola, ao escolher um livro, é obrigada a definir dois títulos de editoras diferentes - a primeira e a segunda opção -, pois a aquisição é realizada por meio de 
licitação. Caso o FNDE não negocie os títulos escolhidos na primeira opção, é encaminhado à escola o livro da segunda. Mas, geralmente, a segunda opção não é a real escolha do professor. Concluída a negociação, as editoras produzem os livros, sob a supervisão do FNDE, enviando-os às escolas nos períodos estabelecidos pelo MEC.

No contexto econômico, o livro didático, no que se refere ao processo de aquisição, constitui-se apenas em uma "mercadoria", submetido às leis do mercado. No momento da negociação entre a editora e o FNDE, a avaliação pedagógica deixa de ser considerada; entretanto, deveria ser prioritária, pois é com base nela que se define o que será trabalhado na escola.

\section{OS PROFESSORES E A SELEÇÃO DOS LIVROS DIDÁTICOS}

São vários os critérios que devem fazer parte da seleção dos livros didáticos. Dentre eles: ideologias intrínsecas, adequação curricular, grau de dificuldade dos textos e exercícios, adequação ao nível de desenvolvimento dos alunos, contextualização da realidade próxima ao aluno, metodologia - tipos de aprendizagem trabalhada (apropriação formal, assimilação, construção) -, ausência de erros conceituais e atualização dos conteúdos, critérios plásticos como estética, diagramação, papel e cores, entre outros.

Discutir esses critérios é, antes de tudo, relacioná-los à formaçáo do professor. Esse profissional deve desenvolver saberes e ter competência para superar as limitaçôes próprias dos livros (Nuñez et al., 2005, p.3).

Considerando dados obtidos por questionários aplicados a professores da rede pública de Goiânia - desenvolvidos para complementar esta pesquisa -, percebe-se que é comum a afirmação de que é importante a consonância do livro didático com o projeto pedagógico da escola. O livro, segundo eles, deve servir não só para eles como para outros professores, refletindo em uma escolha realizada pelos grupos das mesmas áreas. E completam: isso ocorre principalmente naquelas escolas que trabalham no coletivo.

A partir do contexto social e escolar em que se inserem, esses professores fundamentam sua escolha tendo como referência o nível de complexidade e a adequação à realidade do aluno. Eles preferem os livros que se relacionam ao cotidiano do educando, mas, em suas análises, o enfoque dado ao estudo desse cotidiano - de forma investigativa ou ilustrativa -, é pequeno. Logo, não há a preocupação em verificar se os "fatos do cotidiano" saem do superficial e do senso comum, de modo que contribuíssem para uma aprendizagem relevante do ponto de vista do conteúdo. 
Ao definir os conteúdos, sua relevância, atualidade e complexidade - como critérios de seleção dos livros -, é necessário que o professor se questione constantemente sobre a natureza dos conteúdos a serem incorporados, principalmente se estes estáo em sintonia com o tempo em que vivemos e com os alunos que temos.

Em relação aos conteúdos conceituais, os professores manifestam grande fragilidade na escolha. Os resultados apontam para as limitaçóes dos docentes, em razão dos conhecimentos específicos das áreas, como Ciências, Matemática e História, dentre outros, evidenciando sérias lacunas na formação desses profissionais. Essa problemática nos revela ainda: a maior parte dos professores estuda o conteúdo nos próprios livros didáticos, por vezes acompanhados de um guia do livro para o professor.

A falta desses conhecimentos interfere na questão da escolha do livro pelos professores, que preferem aqueles que, do seu ponto de vista, são mais "fáceis”. Assim, muitas vezes, não conseguem identificar um erro conceitual, pois as dificuldades referem-se ao entendimento do próprio conceito.

Considerando os conteúdos relacionados aos valores, é necessário identificar os discursos ideológicos de desrespeito às nossas singularidades, a exemplo da segregação do papel da mulher, do índio e do negro na sociedade. Estes são temas que, dependendo do modo como são apresentados, podem levar os alunos à construção de preconceitos e à não-aceitação das diferenças.

Essas ideologias compóem um possível currículo oculto em que figuram questôes que subjazem aos textos verbais e ilustraçôes dos livros didáticos, mas, por não estarem explícitas, permitem a transmissão de mensagens, contendo significados com os quais os próprios professores podem náo concordar, mas que, sem perceber, promovem sua construção. Essa é exatamente a lógica do currículo oculto, que, por ser naturalizado na cultura, não é visível (Silva, 2000). Nas condições atuais de funcionamento da escola brasileira, o professor passa a ser o grande mediador dos conteúdos ideológicos veiculados pelos livros didáticos, acabando por reproduzir as "verdades" transmitidas por esses instrumentos didáticos.

Pode-se notar nas análises dos professores, relativas a essa temática, que a percepçáo desses discursos depende de quanto o analista foi interpelado por eles. Se, para alguns professores, existe a percepção do currículo subjacente ao texto, com seus valores e ideias constituidores de noçóes sociais, para outros (no caso, a maioria), ao analisar os textos e imagens, essas ideologias são difíceis de serem notadas. A náo-percepçáo desses aspectos está relacionada ao que Bourdieu (1998) chama de conversão do olhar: é preciso perceber que o objeto de análise existe, desnaturalizar o que é natural e, portanto, estranhar para tornar visível. 
A questão dos textos verbais e ilustrações também é analisada, não só na perspectiva das ideologias como da estética, diagramação e conteúdo.

Figuras, gráficos e diagramas devem ser utilizados para facilitar a compreensão dos conteúdos teóricos, procurando, com as ilustraçôes, contextualizar ou vincular esses conhecimentos à prática. Segundo Carneiro (1997, p.368), as imagens podem ser um bom recurso para promover a aprendizagem, mas é necessário compreender a relação entre o texto escrito e as figuras, que devem ter, por vezes, caráter científico. Nos livros didáticos do ensino fundamental, geralmente, a relaçáo texto/ilustração está invertida, privilegiando excesso de ilustrações, o que limita as funções de aprendizagem dos textos escritos.

Considerando os livros das séries iniciais do ensino fundamental, escolhidos pelos professores, percebe-se que, quase sempre, a qualidade gráfica prevalece ao conteúdo. $\mathrm{Na}$ maioria das vezes, a imagem não se constitui em texto não-verbal consistente e chama mais a atençáo do que o texto verbal que traz o conteúdo a ser aprendido. Os professores centram-se mais no aspecto estético do que na capacidade de comunicação da ilustração. Esse fato esbarra, também, na dificuldade do professor em compreender a relação dos textos não-verbais com a aprendizagem.

De acordo com Sacristán (1998, p.38), "o nível e a qualidade das reflexóes dos professores é que permitem a possibilidade de que esses intervenham em uns temas ou outros, uma vez que existam canais de participação".

As dificuldades encontradas pelos professores para analisarem os livros didáticos, pautadas pela ideia de Sacristán, acrescidas pela "intensificação" do seu trabalho e as adversidades que tornam os saberes de sua prática difíceis, transformam os livros didáticos em refúgios que acabam por definir a ação docente. Passando a ser pouco ou nada contestadas, essas dificuldades evidenciam uma problemática na qual se percebe a necessidade de resolver as lacunas na formação docente.

Logo, a questão do livro didático ultrapassa a sua seleção. Passa a incorporar, também, a preparação do professor como profissional capacitado - com seus saberes e competências - para escolher o livro didático. Essa é uma tarefa que não pode ser atribuída, com exclusividade, a um grupo de profissionais monopolizadores de saberes específicos. Aos professores deve ser dada a oportunidade de dominar esses saberes.

\section{CONCLUSÃO}

Na política educacional brasileira, o livro didático é visto como "um dos principais insumos da instituição escolar” (Brasil, 1993, p.25). Entretanto, o MEC, 
usando o argumento de falta de capacitação do professor, estabelece uma política de análise externa à escola. Uma política que deve assegurar a qualidade do conteúdo dos livros didáticos, segundo o ponto de vista das OIs, garantindo, assim, uma escola que mantenha as ideologias do capitalismo.

Portanto, no discurso do MEC, os professores de escolas públicas podem definir livremente quais os autores e editoras seráo utilizados, a cada ano, nas escolas. A escolha, porém, é realizada com base no Guia Nacional do Livro Didático, que é formulado e fornecido pelo FNDE.

O ideário, que parece estar presente nessa pré-seleção, é o de controle sobre o trabalho do professor, sem que ele tenha consciência disso. Um controle curricular! Um controle social! Dessa forma, é possível garantir o direcionamento do trabalho docente pelos pressupostos estabelecidos externamente pelos OIs e pela política educacional brasileira. Com uma formação fragmentada, os professores não terão elementos para questionar esses pressupostos e, principalmente, a eminente necessidade de avaliaçáo e controle do material usado, que se constitui em um dos recursos pedagógicos mais importantes e o mais utilizado nas escolas brasileiras.

A criação do processo de avaliação pelo MEC, num contexto político, acabou por desencadear poderosos mecanismos de reajustamento e adaptaçáo no mercado editorial. Para este segmento, no que se refere às compras do setor público, importa menos a orientação metodológica - ou a ideologia contida em uma coleção didática - e mais a capacidade de vendagem e aceitaçáo no mercado. Nessa perspectiva, o livro didático é visto somente como "mercadoria", sujeita a múltiplas interferências em seu processo de produção e comercialização, o que acarreta um desempenho agressivo de algumas editoras no mercado, que se valem de sofisticados esquemas de distribuiçáo e venda, de tal forma que acabam influenciando decisivamente os processos de escolha nas escolas do País. Naturalmente, as empresas mais bem estruturadas desfrutam de grande vantagem perante as editoras menores.

No âmbito pedagógico, percebe-se que a utilização do guia, pelo professor, ocorre sem a reflexão mais profunda das teorias, filosofias e ideologias que norteiam as obras. As pesquisas indicam que os professores, no estabelecimento dos seus critérios de seleção dos livros-textos, baseiam-se, no julgamento das características cognitivas e psicológicas de seus alunos. Nessa perspectiva, o livro didático é avaliado tendo como referência o aluno, não o professor. Mas a problemática "livro didático" é muito mais delicada: ela atinge os professores de maneira direta, pois muitos deles "fazem desse material didático a sua única fonte de consulta e pesquisa", não conseguindo ir além do diminuto "conhecimento nele presente". 
As respostas da pesquisa nos fazem refletir, mostrando como os aspectos "camuflados" em algumas das açóes do processo de seleçáo podem ser percebidos por nós como educadores. O professor, nesse processo, deve desenvolver saberes e ter competências para superar suas limitações no processo de seleção dos livros. É necessário que ele conquiste seu espaço nas instâncias de decisóes, em âmbitos regional e nacional, e que personifique as reais necessidades do educando, oferecendo respostas às imposições de um mundo em constante transformação.

\section{REFERÊNCIAS BIBLIOGRÁFICAS}

APPLE, Michel W. Trabalho docente e textos: economia política das relações de classe e de gênero em educação. Porto Alegre: Artes Médicas, 1995.

. Conhecimento Oficial: a educação democrática numa era conservadora. Tradução Maria Isabel Eelweiss. Rio de Janeiro: Vozes, 1997.

BOURDIEU, Pierre. O Poder simbólico. Rio de Janeiro: Bertrand Brasil, 1998.

BRASIL. Decreto-lei n. 1.006, de 30 de dezembro de 1938. Estabelece as condições de produção e importação e utilização do livro didático. Lex, v.3, p.1-6, 1938.

BRASIL. Ministério da Educação. Plano Decenal de Educação para Todos (1993-2003). Brasília: MEC, 1993.

- Plano Nacional de Educação: proposta do executivo ao Congresso Nacional. Brasília: Inep, 1998. . Guia do Livro Didático: $1^{\mathrm{a}}$ a $4^{\mathrm{a}}$ série.

Brasília: PNLD, 2001.

BRASIL. Ministério da Educação. Fundo Nacional de Desenvolvimento da Educação. Livro Didático. Disponível em: <http://www. fnde.gov.br/home/ index.jsp?arquivo=livro_ didatico.html> . Acesso em: 1 mar. 2008.

BRASIL. Portaria Normativa n. 7, de 5 de abril de 2007. Dispõe sobre as normas de conduta para o processo de execução dos programas do livro. Diário Oficial [da] República Federativa do Brasil, n.67. Brasília, DF, 9 abr. 2007. Seção 1, p.12-13. CARNEIRO, S. M. H. As Imagens no livro didático.
In: ENCONTRO NACIONAL DE PESQUISA EM ENSINO DE CIÊNCIAS, 1. 1997, Águas de Lindoia. Atas... São Paulo: UFSC, 1997. p. 366-373.

FREITAG, B. et al. O Livro didático em questão. 2. ed. São Paulo: Cortez, 1989.

LINDOSO, Felipe. Uma política para livros. Teoria e Debate: Cultura, n. 23, jan./fev. 1994. Disponível em: <http://www2.fpa. org.br/portal/modules/news/article.php? storyid=1082> Acesso em: 16 de mar. 2009.

MARTINS, Eliecília de Fátima; GUIMARÃES, Gislene Margaret Avelar. As Concepções de natureza nos livros didáticos de ciências. Ensaio: Pesquisa em Educação em Ciências, v. 4, n. 2, p. 1-14, dez. 2002.

MIRANDA, Sonia Regina; LUCA, Tania Regina de. O Livro didático de história hoje: um panorama a partir do PNLD. Revista Brasileira de História, v. 24, n. 48, p. 123-144, 2004.

MORAES, Rita. A Ira dos excluídos. Isto é, jul. 1998.

NUÑEZ, Isauro B. et al. A Seleção dos livros didáticos: um saber necessário ao professor, - caso de ensino de ciências. Revista Iberoamericana de Educação, abr. 2003. Disponível em: <http://www.campus-oei.org/ revistadeloslectores/ 427beltran.pdf $>$. Acesso em: 13 set. 2005

OLIVEIRA, J. B. A.; GUIMARÃES, S. D. P.; BOMERY, H. M. B. A Política do livro didático. Campinas: Summus, 1984.

SACRISTÁN, J. G. O Currículo: uma reflexão sobre a prática. Porto Alegre: Artmed, 1998. 
SCAFF, E. A. S.; SENNA, E. O Guia de livros didáticos e sua (in)utilização no Brasil e no Estado de Mato Grosso do Sul. Tecnologia Educacional, Rio de Janeiro, v. 29, p. 32-37, 2000. SERWY, Alexandre. Os 20 anos do PNLD. In: ENCONTRO TÉCNICO NACIONAL DOS PROGRAMAS DO LIVRO, 9. 2005, Anais... Brasília: MEC/FNDE, 2005.
SILVA, T. T. Teoria cultural e educação: um vocabulário crítico. Belo Horizonte: Autêntica, 2000.

SOARES, M. B. Livro didático: uma história mal contada, fazendo escola. São Paulo: Moderna, 2001. Disponível em: <http://www.moderna. com.br/escola/professor/art02>. Acesso em: 20 dez. 2005.

Recebido em: julho 2008

Aprovado para publicação em: janeiro 2009 
